\title{
Caracterização da Superfície Foliar e das Ceras EPICUTICULARES EM Commelina benghalensis, Ipomoea grandifolia E Amaranthus hybridus ${ }^{1}$
}

\author{
Leaf Surface Characterization and Epicuticular Wax Composition in Commelina benghalensis, \\ Ipomoea grandifolia and Amaranthus hybridus
}

\author{
MONQUERO, P.A. ${ }^{2}$, CHRISTOFFOLETI, P.J. ${ }^{3}$, MATAS, J.A. ${ }^{4}$ e HEREDIA, A. ${ }^{4}$
}

\begin{abstract}
RESUMO - Este estudo teve o objetivo de caracterizar a superficie foliar e a composição de ceras epicuticulares das plantas daninhas Commelina benghalensis, Ipomoea grandifolia e Amaranthus hybridus. As ceras foram extraidas, quantificadas e empregadas em cromatografia de camada delgada, a fim de se determinar a composição química. Partes centrais das folhas foram submetidas à microscopia eletrônica de varredura, para caracterização da superficie foliar adaxial e abaxial. Em A. hybridus as ceras foram constituídas basicamente por substâncias hidrofílicas (álcool, ésteres); a superficie foliar não apresentou tricomas ou glândulas, com grande quantidade de estômatos e as ceras formando pequenos grânulos. I. grandifolia apresentou ceras epicuticulares essencialmente hidrofilicas e superficie foliar rugosa, sem tricomas e sem a presença de cristais de ceras. Em C. benghalensis, as ceras apresentaram na sua constituição química os hidrocarbonos (n-alcanos), sendo, portanto, relativamente mais hidrofóbicas, o que pode influenciar a menor penetração de herbicidas hidrofílicos, como o glyphosate. A superfície foliar apresentou tricomas e estômatos recobertos pela cera epicuticular. Foi observada também a presença de ceras dispersas na superficie adaxial. Com base nos dados obtidos, concluiu-se que um dos mecanismos de tolerância em $C$. benghalensis a herbicidas é a penetração diferencial devido à composição química das ceras epicuticulares, que apresentam componentes de natureza lipofilica em maior concentração que as demais espécies estudadas.
\end{abstract}

Palavras-chave: absorção, tolerância, glyphosate.

ABSTRACT - This study aimed to characterize the foliar surface and the epicuticular wax composition of the weeds Commelina benghalensis, Ipomoea grandifolia and Amaranthus hybridus. The epicuticular waxes were extracted, quantified and submitted to thin layer chromatography in order to determine the chemical composition. Central parts of the leaves were submitted to electron microscopy to characterize the adaxial and abaxial foliar surface. In A. hybridus the waxes were constituted mostly by hydrophilic substances (alcohols, steres), and absence of tricomes and glandules on the foliar surface, with a great number of stomata and waxes were in the small grains. I. grandfolia presented epicuticular waxes formedchemically by alcohols and esters and a coarse e foliar surface, without trichomess and wax crystals. In C. benahalensis, the waxes presented hydrocarbons (n-alkenes) in their chemical constitution, being relatively more hydrophobic, what can influence the lower penetration of hydrophilic herbicides such as glyphosate. The foliar surface presents trichomess and a lower number of stomata. All the stomata were recovered by epicuticular wax, being possible to observe the presence of dispersed wax on the adaxial surface. Based on the data obtained, it can be concluded that one of the tolerance mechanisms to herbicides in $\mathbf{C}$. benghalensis is the differential penetration due to the chemical composition of the epicuticular waxes, which contain lipophilic components in higher concentration than the other studied species.

Key words: absorption, tolerance, glyphosate.

Recebido para publicação em 8.12.2003 e na forma revisada em 18.6.2004.

2 Professora substituta do Departamento de Recursos Naturais do Centro de Ciências Agrárias - CCA-UFSCar, Rodovia Anhanguera, Km 174, 13600-970 Araras-SP, <pamonque @ hotmail.com>; ${ }^{3}$ Professor Associado do Dep. de Produção Vegetal da Universidade de São Paulo, Escola Superior de Agricultura “Luiz de Queiroz”, Piracicaba-SP, Brasil. ${ }^{4}$ Departamento de Bioquímica e Biologia Molecular, Universidad de Málaga - Espanha. 


\section{INTRODUÇÃO}

Como conseqüência da evolução química e biológica, os organismos vivos têm desenvolvido uma série de estruturas de natureza polimérica, que os isolam e os protegem do meio externo. Nas plantas superiores essa função é assumida pela cutícula vegetal ou membrana cuticular (Heredia et al., 1998). De modo geral, desde o interior até o exterior, a membrana é constituída por cutícula secundária (capa cuticular cutinizada), cutícula primária (cutícula propriamente dita) com ceras embebidas e, na parte mais externa, as ceras epicuticulares. A composição química da membrana cuticular é variada, sendo os componentes principais a cutina e as ceras. A cutina é um biopoliéster insolúvel de elevado grau de entrecruzamento entre os ácidos graxos hidroxilados de cadeia longa que a compõem, enquanto as ceras aparecem embebidas neste polimero (intracelulares) ou depositadas no exterior da cutícula (epicuticulares). As ceras epicuticulares podem ser depositadas em uma variedade de formas físicas. Em algumas plantas, formam camadas finas, e em outras podem formar placas ou cristais de diferentes tamanhos e formas.

Devido à sua composição química, que se reflete no grau de cristalinidade, e à possibilidade de constituir na superficie da membrana cuticular uma película que atua como interfase entre a célula vegetal e o meio, as ceras se destacam como a principal barreira protetora contra perda de água por transpiração excessiva, ação de patógenos, radiações solares e entradas de produtos químicos e contaminantes (Heredia et al., 1998).

O conhecimento das propriedades protetivas da cutícula requer também entendimento da composição das ceras cuticulares e da superficie foliar. Nos últimos anos, a composição qualitativa e quantitativa das ceras de mais de 80 espécies de plantas e as características da superficie foliar têm sido determinadas. As taxas de absorção foliar e, portanto, da eficácia biológica da aplicação de pesticidas depende, em grande parte, do tipo de estrutura encontrada nas folhas e da permeabilidade das cutículas de culturas e plantas daninhas (Baker, 1982).

Planta Daninha, Viçosa-MG, v.22, n.2, p.203-210, 2004
As ceras epicuticulares são constituídas de um filme de cera amorfa, de onde emergem estruturas cristalinas de diferentes formas. As estruturas mais freqüentemente observadas são os túbulos, placas ou lamelas, bastonetes, filamentos, grânulos de forma determinada ou não. Apesar de a morfologia das ceras ser controlada geneticamente, a quantidade e a distribuição podem ser modificadas pelas condições ambientais (Barthlott et al., 1998).

No Brasil, a tolerância ao glyphosate tem sido detectada em algumas espécies de plantas daninhas (Santos et al., 2001; Durigan et al., 1988, Monquero, 2003). Entretanto, a razão para essa tolerância diferencial não foi ainda totalmente compreendida.

Há vários exemplos na literatura demonstrando que a tolerância de plantas daninhas ao glyphosate se deve a uma penetração ou a uma translocação diferencial (Sandberg et al., 1980; Chachalis et al., 2001). Satichivi et al. (2000) observaram que a absorção foliar de ${ }^{14} \mathrm{C}$-glyphosate, 72 horas após a aplicação, foi maior em Setaria faberi (43\%) do que em Abutilon theophrasti (26\%). Estes mesmos pesquisadores constataram que a adição de $1 \%$ de sulfato de amônio aumentava a absorção de glyphosate em ambas as espécies.

A absorção e translocação diferencial de glyphosate foram citadas como a principal razão para a tolerância diferencial de plantas como Apocynum cannabium, Asclepsias syriaca e Abutilon theophrasti (Wyrill \& Burnside, 1976).

Monquero (2003), estudando a absorção, a translocação e o metabolismo de ${ }^{14} \mathrm{C}$-glyphosate pelas plantas daninhas $\mathrm{C}$. benghalensis e I. grandifolia, concluiu que o principal mecanismo de tolerância de $C$. benghalensis ao glyphosate foi a absorção diferencial e o metabolismo do herbicida por esta planta. Em I. grandifolia a tolerância ocorreu devido a uma menor translocação do herbicida, não havendo evidências de metabolismo diferencial do herbicida por esta planta.

O objetivo deste experimento foi caracterizar a superficie foliar e a composição das ceras epicuticulares das plantas daninhas C. benghalensis, I. grandifolia e A. hybridus, 
correlacionando-as com a absorção diferencial do glyphosate entre essas espécies.

\section{MATERIAL E MÉTODOS}

Os estudos de caracterização das ceras epicuticulares e da superficie foliar foram conduzidos nos laboratórios e nas instalações do Departamento de Bioquímica e Biologia Molecular, Universidad de Málaga, Espanha, sob a orientação do Prof. Antonio Heredia.

\section{Caracterização das ceras epicuticulares}

As ceras epicuticulares foram extraídas de 20 plantas de C. benghalensis, I. grandifolia e A. hybridus que se desenvolveram em câmara de crescimento com temperatura dia/noite de $32 / 18{ }^{\circ} \mathrm{C}$, respectivamente, fotoperiodo de 16 horas de luz $\left(350 \mu \mathrm{mol} \mathrm{m} \mathrm{m}^{-2} \mathrm{~s}^{-1}\right)$ e umidade relativa constante de $80 \%$, irrigando-se diariamente, visando a manutenção da umidade satisfatória. As análises foram feitas quando as plantas apresentaram quatro folhas verdadeiras, seguindo a metodologia proposta por Hamilton (1995), com algumas modificações. As folhas de cada espécie de planta foram introduzidas separadamente em placas com clorofórmio e metanol (90:10 mL) por 30 segundos, agitando-se levemente. Esses procedimentos foram feitos cuidadosamente para se evitar a ruptura das folhas e a conseqüente liberação de clorofila e outros compostos. Os extratos obtidos foram filtrados e deixados evaporar sobre uma placa a $55^{\circ} \mathrm{C}$, até reduzir o volume para aproximadamente $15 \mathrm{~mL}$. Esta solução (clorofórmio+ceras) foi transferida para vials de $25 \mathrm{~mL}$ de peso conhecido. O clorofórmio foi evaporado em temperatura ambiente e os vials foram mantidos para pesagem dois e quatro dias após a obtenção do resíduo sólido (ceras). A quantificação das ceras foi expressa por quantidade de ceras por unidade de área foliar $\left(\mu \mathrm{g} . \mathrm{cm}^{-2}\right)$. Para isso, a área das folhas de cada espécie, utilizadas para a extração das ceras, foi medida através do aparelho fotoelétrico de medição de área foliar LICOR-3100. O experimento foi conduzido em delineamento inteiramente casualizado, com quatro repetições para cada espécie. Foram calculadas as médias das quatro repetições, juntamente com os respectivos desvio-padrões.
Para a análise química das ceras, os resíduos sólidos (ceras) obtidos foram ressuspendidos com $500 \mu \mathrm{L}$ de clorofórmio e utilizados em cromatografia de camada delgada. Os extratos de cada espécie foram aplicados em dois volumes diferentes $(250$ e $500 \mu \mathrm{L})$ sobre cromatoplacas, TLC plates $5 \times 10 \mathrm{~cm}$ Sílica gel $60 \mathrm{~F}_{254}$, Merck, que foram previamente ativadas por aquecimento a $100^{\circ} \mathrm{C}$. Como fase móvel foram empregados $8 \mathrm{~mL}$ de benzeno. Após a migração das amostras, a placa foi retirada do benzeno e banhada por uma solução de TLC (94 mL de água, $6 \mathrm{~mL}$ de $\mathrm{H}_{2} \mathrm{SO}_{4}, 1,5 \mathrm{~g}$ de $\mathrm{H}_{3} \mathrm{Mo}_{12} \mathrm{O}_{40} \mathrm{P}$ e $\left.1 \mathrm{~g} \mathrm{de} \mathrm{Ce}_{2}\left(\mathrm{SO}_{4}\right)_{3}\right)$. Por último, a placa foi seca, primeiro, em temperatura ambiente e posteriormente a $100{ }^{\circ} \mathrm{C}$, para o aparecimento das bandas. Para a determinação do Rf (razão de fluxo), segundo a fórmula sugerida por Collins et al. (1990): Rf= (Distância percorrida pela amostra)/(Distância percorrida pelo eluente), marcou-se a distância percorrida pela fase móvel e pelas bandas nas cromatoplacas.

\section{Caracterização da superfície foliar por microscopia eletrônica de varredura}

As plantas C. benghalensis, I. grandifolia e A. hybridus, desenvolvidas em condições já mencionadas, apresentando quatro folhas verdadeiras, foram utilizadas neste experimento. Amostras de $1 \mathrm{~cm}^{2}$ foram cortadas da região central de folhas jovens, porém totalmente expandidas, fixadas em pequenos cilindros de alumínio (stubber) e recobertas com uma capa de ouro de espessura de 0,05 $\mu \mathrm{m}$. Dessa forma, as amostras foram observadas em microscópio eletrônico de varredura JEOL JSM-840 (JeolJapão), empregando-se $15 \mathrm{kV}$ e sendo fotografadas as melhores imagens.

\section{RESULTADOS E DISCUSSÃO}

\section{Caracterização das ceras epicuticulares}

A quantidade de ceras por unidade de área foliar foi maior em I. grandifolia $\left(37,0 \mu \mathrm{g} \mathrm{cm}^{-2}\right)$, seguida por $C$. benghalensis $\left(34,5 \mu \mathrm{g} \mathrm{cm}^{-2}\right) \mathrm{e}$ A. hybridus (31,7 $\left.\mu \mathrm{g} \mathrm{cm}^{-2}\right)$ (Figura 1). A quantidade de ceras epicuticulares na maioria das espécies varia de 10 a $200 \mu \mathrm{g} \mathrm{cm}^{-2}$ (McWhorter $\&$ Ouzts 1993), embora quantidades acima de 
$300 \mu \mathrm{g} \mathrm{cm}^{-2}$ já tenham sido relatadas (Baker, 1982).

As ceras epicuticulares de $A$. hybridus, $C$. benghalensis e $I$. grandifolia são constituídas de maneira geral de hidrocarbonos, álcoois e ésteres, com uma clara distinção entre as espécies (Figura 2). Quanto maior o valor de Rf, mais apolar é o constituinte químico e, portanto, mais hidrofóbica é a cera. Em $C$. benghalensis, as ceras epicuticulares possuíram na sua composição n-alcanos

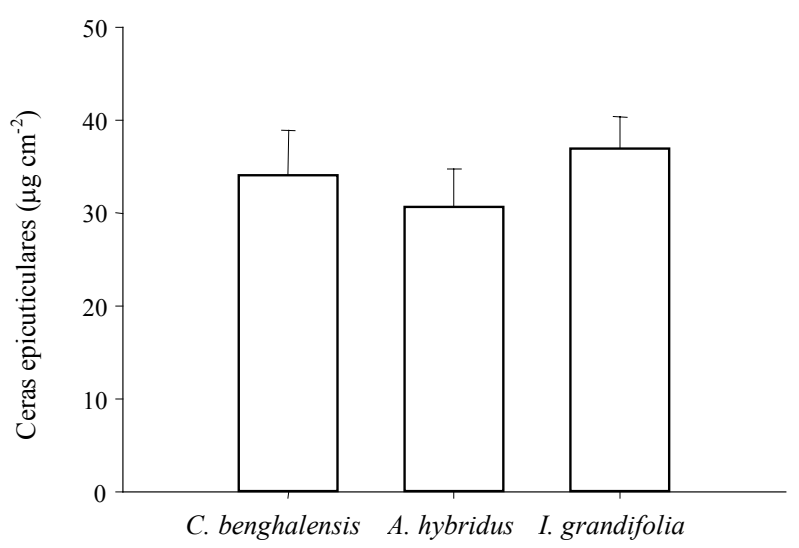

Figura 1 - Quantidade de ceras epicuticulares $\left(\mu \mathrm{g} \mathrm{cm}^{-2}\right)$ nas plantas daninhas estudadas.
$(\mathrm{Rf}=0,9)$, que são compostos altamente hidrofóbicos. É importante lembrar que o glyphosate é altamente hidrofilico (Sandberg et al., 1980); portanto, uma das razões da menor absorção do glyphosate por esta planta (66\% do ${ }^{14} \mathrm{C}$-glyphosate aplicado foi absorvido), relatada por Monquero (2003), foi a composição química das ceras epicuticulares. De acordo com Hamilton (1995), os hidrocarbonos (n-alcanos) estão presentes em quase toda a superfície lípidica das plantas, variando quantitativamente de traços até 50\% de toda a planta, porém são predominantes em poucos casos. As ceras, em I. grandifolia e A. hybridus, foram compostas basicamente por álcoois primário e secundário $(\mathrm{Rf}=0,1$ e 0,4$)$ e ésteres $(0,8)$. Esses compostos não são barreiras para a penetração do herbicida glyphosate, já que são hidrofílicos. Os álcoois são, na maioria dos casos, os principais componentes das ceras, variando de pequenas porcentagens até 60\% das ceras totais, dependendo da espécie. Em plântulas de milho, por exemplo, constituem $63 \%$ de toda a cera epicuticular, um valor que chega a $14 \%$ em folhas imaturas. Ésteres podem chegar até a $80 \%$ da cera total, e os ácidos podem estar presentes em grande proporção - um exemplo são as folhas de sorgo, que possuem cerca de $40 \%$ de ácidos

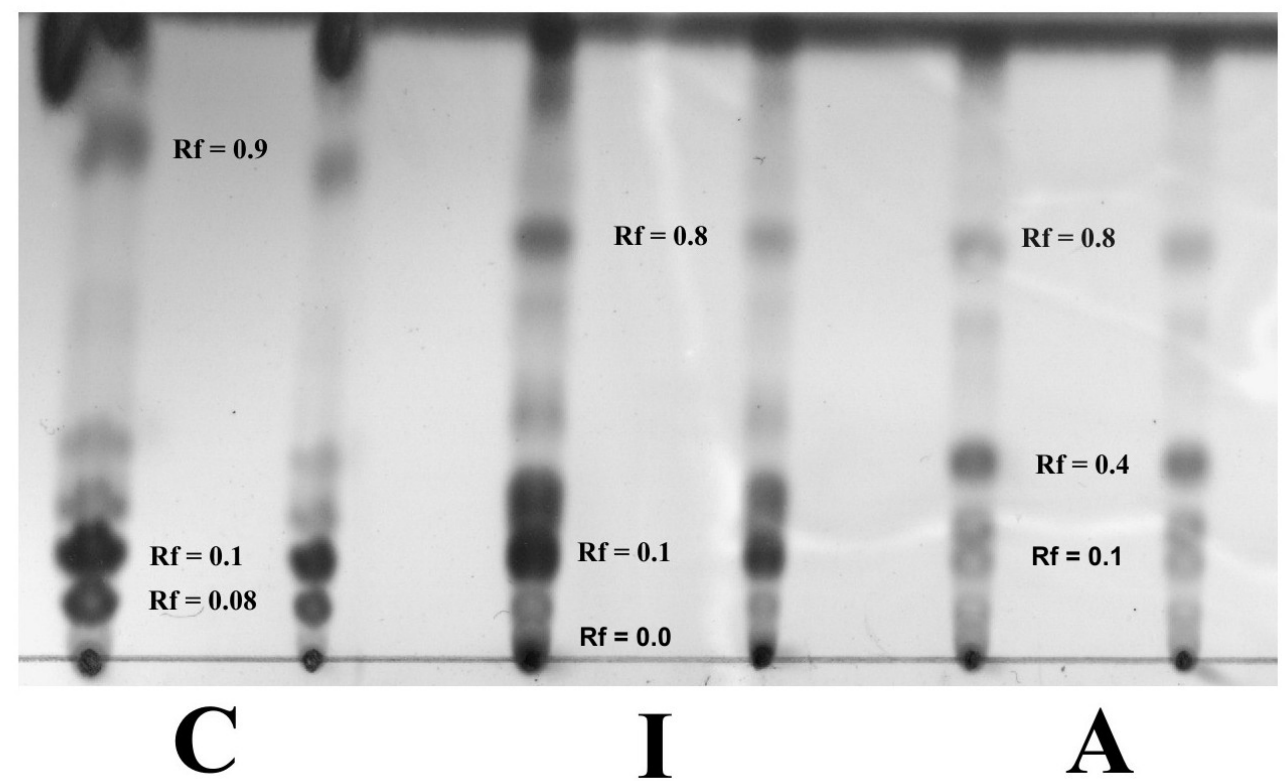

Figura 2 - Cromatografia de camada delgada de ceras epicuticulares com valores de $\mathrm{Rf}$. $\mathrm{C}=$ C. benghalensis; $\mathrm{I}=$ I. grandifolia; $\mathrm{A}=$ A. hybridus. 
na composição das ceras epicuticulares (Hamilton, 1995).

A composição química das ceras epicuticulares é variável entre os distintos grupos filogenéticos, ocorrendo diferenças também dentro dos mesmos grupos, espécies, ou nos diferentes estádios de crescimento de um mesmo indivíduo. Os principais componentes químicos das ceras epicuticulares são n-alcanos, ésteres, álcoois e ácidos graxos. A importância da composição química destas ceras está relacionada com a sua morfologia. Os hidrocarbonos e álcoois primários, por exemplo, cristalizam na forma de placas; os álcoois secundários e as cetonas, como túbulos; os aldeídos, na forma de grânulos; e os dioles, como pequenas tiras. No caso dos triterpenóides e acil ésteres, não há a formação de cristais, sendo as estruturas majoritariamente amorfas (Chachalis et al., 2001).

Mendonça (2000), estudando algumas características da superficie foliar de várias espécies daninhas, observou que $C$. benghalensis foi a que apresentou ceras epicuticulares com maior porcentagem de compostos apolares, o que pode prejudicar a absorção de herbicidas com baixo Kow. De acordo com Silva et al. (2000), os herbicidas lipofilicos (alto Kow) se solubilizam nos componentes lipofilicos da cutícula e se difundem através desta. Com relação aos herbicidas hidrofilicos, admite-se que a cutícula tenha uma estrutura porosa, que se mantém hidratada, dependendo das condições ambientais, sendo esta água de hidratação da cutícula a rota de penetração hidrofilica. Velini \& Trindade (1992) citam como outra possivel rota de absorção dos herbicidas polares os filamentos de pectina dispersos na matriz da cutina, que podem cruzar toda a cutícula. Esses filamentos, desde que hidratados, podem atuar como via de transporte desses produtos.

Algumas pesquisas demonstraram que a composição das ceras pode mudar com a idade das plantas. Em Sorghum halepenses, alcanos e ácidos aumentaram, enquanto houve diminuição de álcoois em ceras de folhas mais velhas (McWorter \& Ouzts, 1993). Portanto, pode-se correlacionar o fato de a $C$. benghalensis ser mais tolerante ao glyphosate quando adulta com uma maior quantidade de alcanos nas folhas maduras.

\section{Caracterização da superficie foliar por microscopia eletrônica de varredura}

A superfície foliar das plantas C. benghalensis, I. grandifolia e A. hybridus apresentaram diferença marcante em sua micromorfologia. A superfície adaxial de C. benghalensis apresentou elongados tricomas e um pequeno número de estômatos distribuídos em fileiras, recobertos por uma camada de cera epicuticular (Figura 3). O menor número e a obstrução dos estômatos pelas ceras de natureza hidrofóbica são uma provável causa da menor absorção do herbicida glyphosate através da membrana cuticular que cobre as células-guarda. Podem-se observar também camadas de ceras na superficie adaxial em forma de filamentos pouco definidos. Santos et al. (2002) observaram, nesta planta, pêlos tectores, que são de dois tipos: longos com extremidade afilada e curtos com extremidade curva - os pêlos longos concentraram-se na epiderme abaxial e os pêlos curtos, na epiderme abaxial. Em I. grandifolia, a superfície adaxial de folhas jovens se apresentou de maneira rugosa, sem a presença de tricomas ou glândulas (Figura 4). Os estômatos sem qualquer tipo de obstrução foram observados em maior quantidade, quando comparado a C. benghalensis. Deposição cristalina de ceras não foi observada; ceras amorfas também foram identificadas em outras espécies de plantas como Vitis vinifera, Beta vulgares e Trifolium repens. Todas essas espécies apresentaram um ponto em comum: a grande quantidade de álcool primário na composição de ceras. Há a hipótese de que a natureza amorfa das ceras pode ser uma conseqüência da baixa quantidade de ceras na superficie foliar ou decorrente da composição química (Baker \& Bukovac, 1971).

Procópio et al. (2003) observaram que a principal barreira foliar à penetração de herbicidas em Galinsoga parviflora foi a baixa densidade estomática na face adaxial; no caso de Crotalaria incana, o principal obstáculo à penetração de herbicidas foi a grande quantidade de ceras epicuticulares. Já em relação a Conyza bonariensis a alta densidade tricomática, a grande espessura da cutícula na fase adaxial e a baixa densidade estomática foram as principais barreiras à penetração dos herbicidas. Em Ipomoea cairica, a grande espessura 

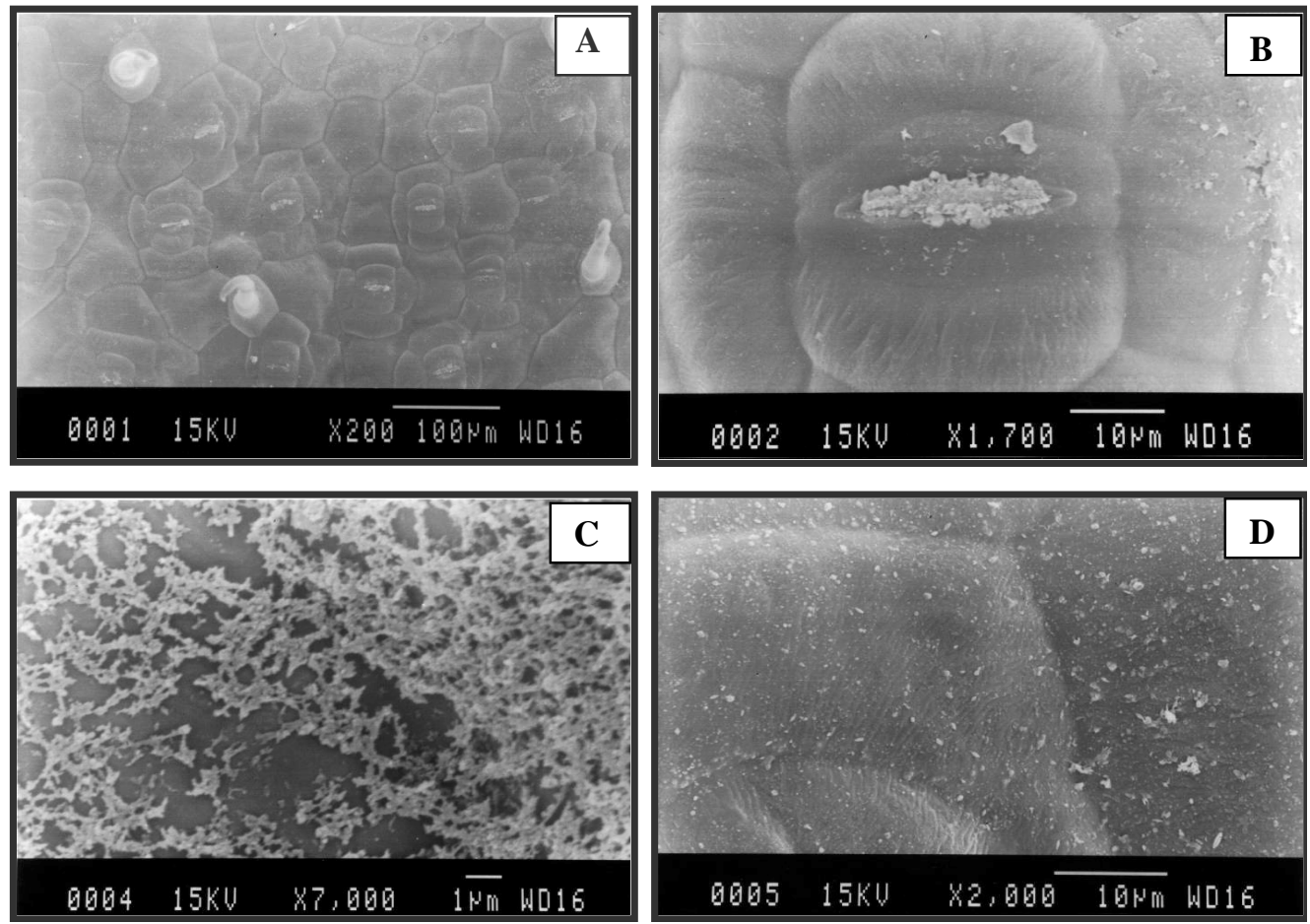

Figura 3 - Superfície foliar de $C$. benghalensis. (A) vista geral da superfície adaxial; (B) detalhe de estômato recoberto por ceras; (C) detalhes das ceras epicuticulares da superfície adaxial; (D) detalhes das ceras na superfície abaxial.
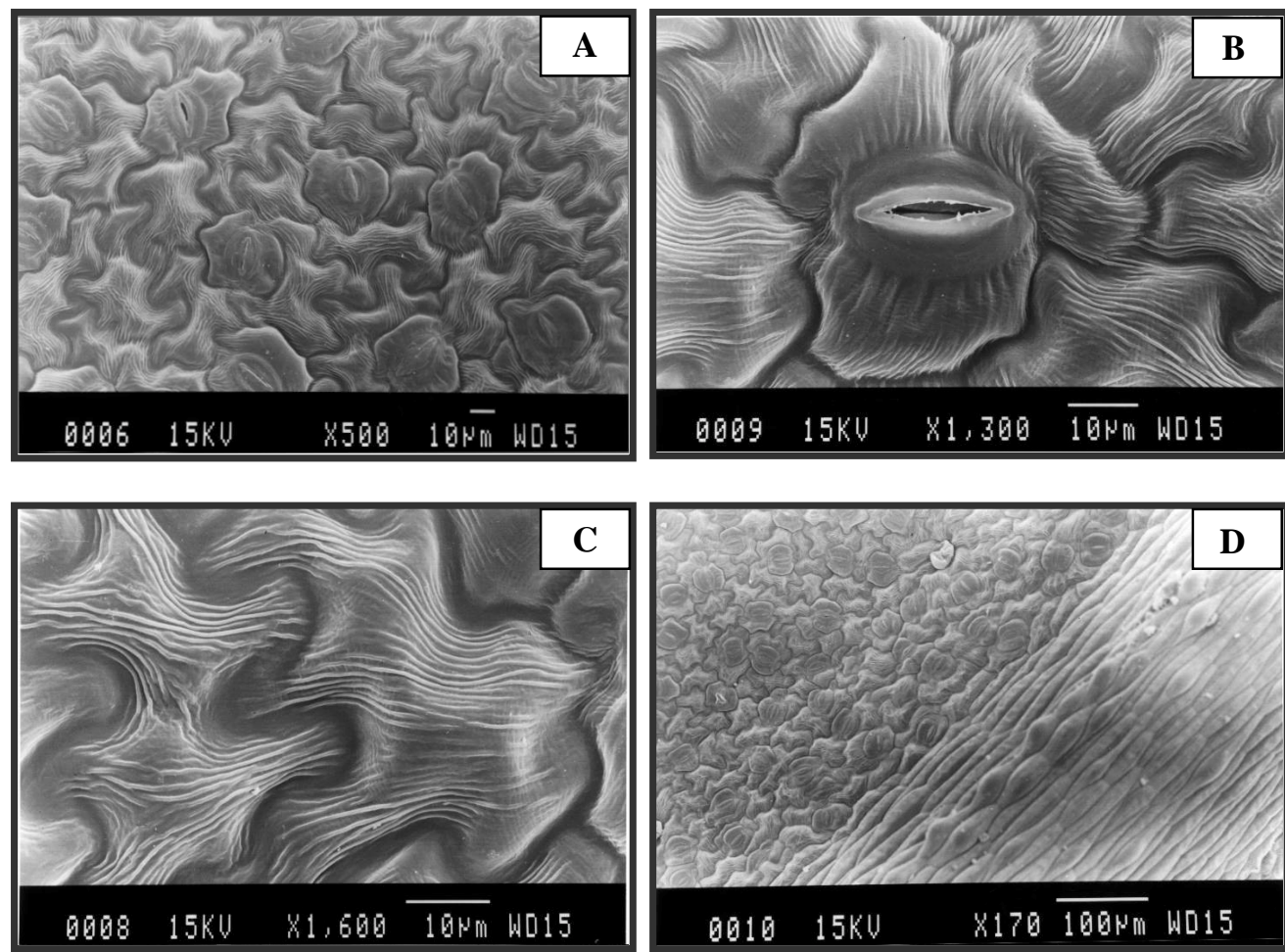

Figura 4 - Superfície foliar de I. grandifolia. (A) vista geral da superfície adaxial; (B) detalhe de um estômato; (C) superfície adaxial sem presença de cristais de ceras; (D) detalhes da superfície abaxial. 
da cutícula na fase adaxial e a baixa densidade estomática foram os possiveis obstáculos a penetração de herbicidas aplicados em pósemergência.

A superficie foliar de A. hybridus apresentou-se lisa, sem a presença de tricomas ou glândulas e com grande quantidade de ceras granulares tanto na superficie adaxial como na abaxial (Figura 5). Os estômatos se encontraram em depressão em relação à superficie foliar, rodeados por cristais de forma alongada.
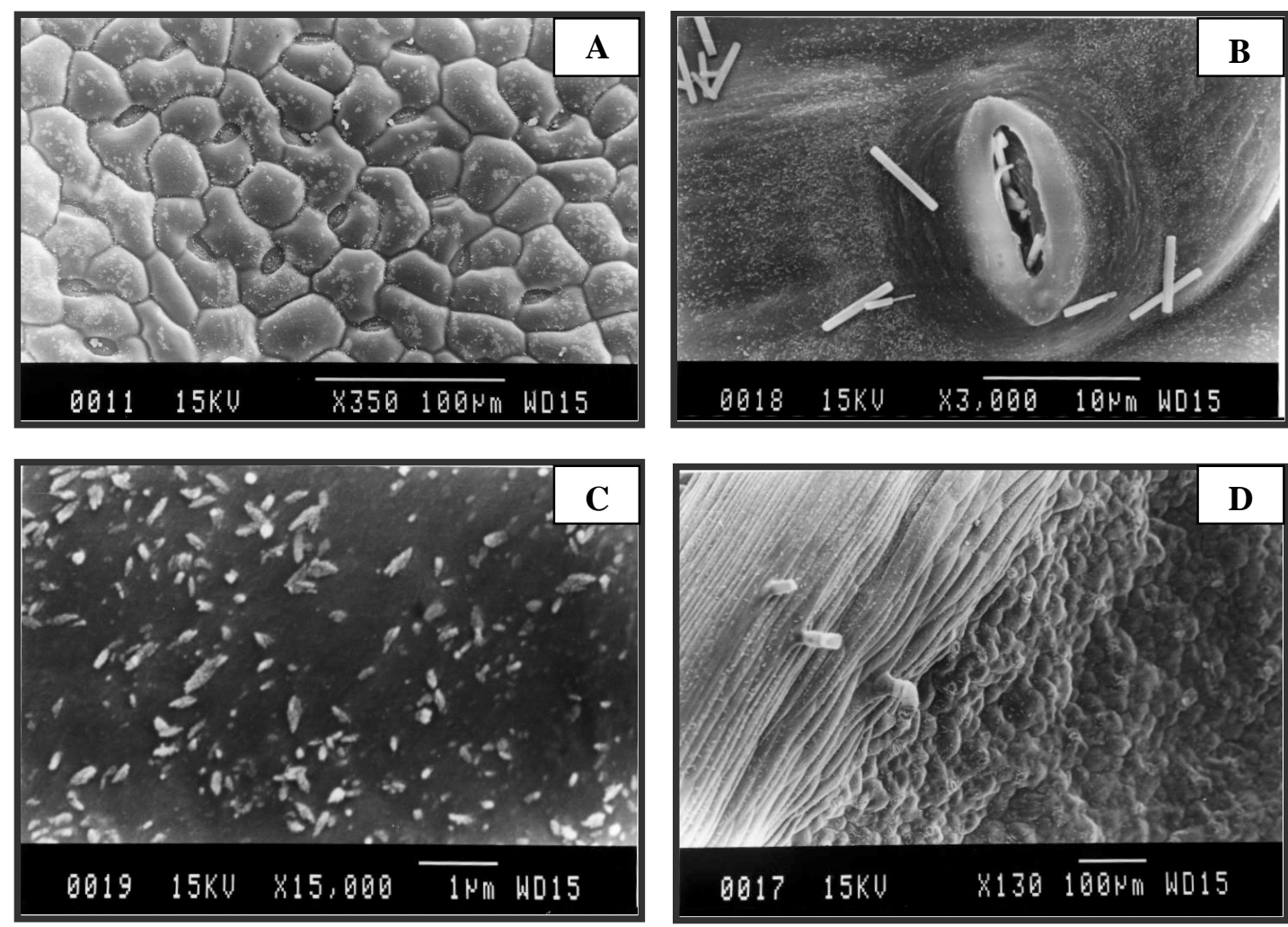

Figura 5 - Superfície foliar de A. hybridus. (A) vista geral da superfície adaxial; (B) detalhe de um estômato com ceras ao redor; (C) superfície adaxial com cristais de ceras; (D) detalhes da superfície abaxial.

\section{LITERATURA CITADA}

BAKER, E. A. Chemistry and morphology of plant epicuticular waxes. In: CUTLER, D. F.; ALVIN, K. L.; PRICE, C. E. (Eds.) The plant cuticle. London : Academic Press, 1982. p. 140-161.

BAKER, E. A.; BUKOVAC, M. J. Characterization of the components of plant cuticles in relation to the penetration of 2,4-D. Ann. App. Biol., v. 67, p. 243-253, 1971.

BARTHLOTT, W. et al. Classification and terminology of plant epicuticular waxes. J. Linn. Soc. Bot., v. 126, p. 237 $260,1998$.
CHACHALIS, D.; REDDY, K. N.; ELMORE, C. D. Characterization of leaf surface, wax composition, and control of redvine and trumpetcreeper with glyphosate. Weed Sci., v. 49, p. 156-163, 2001.

COLLINS, C. H.; BRAGA, G. L.; BONATO, P. S. Introdução aos métodos cromatográficos. 4.ed. Campinas: UNICAMP, 1990. 279 p.

DURIGAN, J. C; GALLI, A. J. B.; LEITE, G. J. Avaliação da eficiência da mistura de glyphosate e 2,4-D para o controle de plantas daninhas em citros. In: CONGRESSO BRASILEIRO DE HERBICIDAS E PLANTAS DANINHAS, 17., 1988. Piracicaba. Resumos... Piracicaba: SBHED, 1988. p. 303-304. 
HAMILTON R. J. Waxes: chemistry, molecular biology and functions. Edinburgh: Orly Press, 1995. 349 p.

HEREDIA, A. et al. La cutícula vegetal: estructura y funciones. Ecologia, v. 12, p. 293-305, 1998.

MCWHORTER, C. G.; OUZTS, C. Leaf surface morphology of Erythroxylum sp. and droplet spread. Weed Sci., v. 42, p. 18-26, 1993.

MENDONÇA, G. G. Algumas características da superfície foliar de diversas plantas daninhas monocotiledôneas. 2000. 89 f. Dissertação (Mestrado em Fitotecnia) - Universidade Estadual Paulista, Botucatu, 2000.

MONQUERO, P. A. Dinâmica populacional e mecanismos de tolerância de espécies de plantas daninhas ao herbicida glyphosate. 2003. $99 \mathrm{f}$. Tese (Doutorado em Fitotecnia) - Escola Superior de Agricultura "Luiz de Queiroz", Piracicaba, 2003.

PROCÓPIO, S. O. et al. Estudos anatômicos de folhas de espécies de plantas daninhas de grande ocorrencia no Brasil. III -Galinsoga parviflora, Crotalaria incana, Conyza bonariensis e Ipomoes cairica Planta Daninha, v. 21, n. 1, p. 1-9, 2003 .

SANDBERG, C. L.; MEGGITT, W. F.; PENNER, D. Absorption, translocation and metabolism of 14Cglyphosate in several weed species. Weed Res., v. 20, p. $195-200,1980$
SANTOS, I. C. et al. Eficiência de glyphosate no controle de Commelina benghalensis e Commelina diffusa. Planta Daninha, v. 19, n. 1, p. 135-143,2001.

SANTOS, I. C. et al. Caracteres anatômicos de duas espécies de trapoeraba e eficiência do glyphosate. Planta Daninha, v. 20, n. 1, p. 1-8, 2002.

SATICHIVI, N. et al. Absorption and translocation of glyphosate isopropylamine and trimethysulfonium salts in Abutilon theophrasti and Setaria faberi. Weed Sci., v. 48, p. 675-679, 2000.

SILVA, A. A. et al. Controle de plantas daninhas. Brasília: ABEAS, 2000. 260 p.

VELINI E. D.; TRINDADE, M. L. B. Comportamento de herbicidas na planta. Épocas de aplicação de herbicidas. In: SIMPOSIO NACIONAL SOBRE MANEJO INTEGRADO DE PLANTAS DANINHAS EM HORTALIÇAS, 1992, Botucatu. Anais... Botucatu: UNESP, 1992. p. 65-86.

WYRILL, J. B. III.; BURNSIDE, O. C. Absorption, translocation and metabolism of 2,4 D and glyphosate in common milkweed and hemp dogbane. Weed Sci., v. 24, p. $557-566,1976$ 